\title{
Efficacy of Some Microbial Insecticides on Pupation Success of Diamond Back Moth (Plutella xylostella L.)
}

\author{
Subhadip Sen ${ }^{*}$, Nilima Karam ${ }^{1}$ and K. I. Singh ${ }^{2}$ \\ ${ }^{1}$ AICRP on soybean, Directorate of Research, ${ }^{2}$ Department of Entomology, Central \\ Agricultural University, Imphal, Manipur, India \\ *Corresponding author
}

\section{A B S T R A C T}

Keywords

Diamondback moth, Pupation success, Bacillus thuringiensis, Beauveria bassiana, Metarhizium anisopliae

Article Info

\section{Accepted:}

20 December 2020 Available Online: 10 January 2021
The efficacy of three commercial microbial formulations viz., Bacillus thuringiensis, Beauveria bassiana and Metarhizium anisopliae were evaluated at different doses on the percent pupation success of diamondback moth. These formulations were tested on 6 days old larvae of the pest in the laboratory of Department of Entomology, College of Agriculture, Central Agricultural University, Imphal during 2019-2020. In the present investigation it was observed that all the microbial formulations were effective to suppress pupation as compared to control treatment. At 72 days after treatment, larvae initiated pupation. After 144 hours of treatment, least pupation was observed with Beauveria bassiana @4g/l (25.00\%) whereas all doses of M.anisopliae and B. thuringiensis reported percent pupation success ranging from $45-52.50 \%$ and 42.50-60\% respectively. Considering the parameter mentioned, it was concluded that Beauveria bassiana was the most effective microbial insecticide to retard pupation of diamondback moth, followed by M. anisopliae and B.thuringiensis.

\section{Introduction}

Cabbage (Brassica oleracea var. capitata) is an important cruciferous crop belonging to the family Brassicaceae. It is a widely cultivated vegetable crop all over the world. Diamondback moth (Plutella xylostella L.) is one of the major pests of all cruciferous crops (Talekar and Shelton, 1993).In 1914, Diamondback moth (DBM) was first reported in India on cruciferous vegetables (Fletcher, 1914). DBM, a cosmopolitan and destructive pest on crucifers (Vanderberg et al., 1998), can survive in all the agro-climatic zones of India. The pest infestation can be seen from February to April in summer crops and September to December in winters (Gill et al., 2008). The infestation starts from the nursery. The pest caused nearly 52\% loss of marketable yield in cabbage in India (Krishnakumar et al., 1986). Economic Threshold Level of the pest is 2-5 larvae/plant (Rejesus et al., 1995).

To control the pest, farmers rely heavily on the use of synthetic insecticides. But due to 
resistance developed by this insect, conventional use of these insecticides often failed. DBM was the first insect to develop resistance to DDT and this was reported from Indonesia (Ankersmit, 1953). Moreover, these synthetic insecticides have hazardous effects on non-target organisms like beneficial insects, mammals as well as humans. To justify this, the focus should be diverted to use of eco-friendly means of pest control. Biological control of insect pests with microorganisms is more specific, economical and less hazardous to the ecosystem (Castillo et al., 1997). The use of entomopathogenic microorganisms proves to be more efficient. Entomopathogenic microbes like Bacillus thuringiensis, Metarhizium anisopliae and Beauveria bassiana have a prospect to control the pest without causing harm to nature and other lives.

\section{Materials and Methods}

The study was undertaken at College of Agriculture, Central Agricultural University, Imphal, under laboratory conditions of Department of Entomology at ambient temperature and relative humidity. For the study, larvae and pupae were collected from untreated farmer's fields growing cabbage and cauliflower and collected larvae were reared on clean cabbage leaf pieces. The larvae were allowed to pupate. The emerged moths were released in insect rearing cage containing 4-5 leaf stage of cabbage plant for oviposition. The hatched larvae were reared on pieces of cabbage leaves. Ten number of DBM larvae were taken in each replication. Six days old larvae ( $2^{\text {nd }}$ instar) were taken for the study as they are easy to handle and moreover DBM takes around 10-12days to complete its larval period. The commercial formulations of the entomopathogenic microbial insecticides namely, Green Lipel (Bacillus thuringiensis), Multiplex Baba (Beauveria bassiana) and Green Pacer
(Metarhizium anisopliae) were collected from the market. Three doses for each microbial formulations i.e., $1 \mathrm{~g} / 1,1.5 \mathrm{~g} / \mathrm{l}$ and $2 \mathrm{~g} / 1$ of Green Lipel and $3 g / 1,4 g / 1$ and $5 g / 1$ each of Multiplex Baba and Green Pacer were taken to study their efficacy and was compared with untreated control treatment. The treatments were replicated four times and was subjected to Complete Randomized Design for statistical analysis. Leaf dip method of bioassay technique was employed for Bacillus thuringiensis treatments (Sharma et al., 2000) and direct spray method on insect technique was employed for fungal microbial insecticides viz., Beauveria bassiana and Metarhizium anisopliae. For the control treatment, leaf discs were dipped in distilled water and fed to the larvae. The pupation data was recorded up to 144 hours (6 days) of treatment and percent pupation success was calculated by following the method:-

Number of pupae obtained / Number of larvae taken $\mathrm{x} 100$

\section{Results and Discussion}

The study on the effect of different doses of some microbial insecticides on pupation success of DBM larvae is presented in Table (1). The data recorded during the investigation indicated that percent pupation was low in all microbial treatment as compared to control treatment. At 24 hours (1 day) and 48 hours (2days) after treatment, none of the larva had undergone pupation in all the treatments. At 72 days (3 days) after treatment, larvae initiated pupation with pupation percentage being low ranging from $7.50 \%$ - $40.00 \%$ only. Percent pupation success was however non-significant in all the treatments. Pupation of DBM ranged from $15.00 \%$ to $87.50 \%$ in the microbial treatment at 96 hours (4 days) after treatment. Least pupation was observed with $B$. bassiana $@ 4 \mathrm{~g} / \mathrm{l}$ that gave $15.00 \%$ pupation success. $B$. 
bassiana @3g/1 (55.00\%) recorded the highest pupation percentage among the tested microbial insecticides. After 120 hours (5 days) of treatment, the least percent pupation was observed with treatment $B$. bassiana $@ 4 \mathrm{~g} / \mathrm{l}(22.50 \%)$. The remaining order of percent pupation success was $B$. thuringiensis $@ 1.5 \mathrm{~g} / 1, \quad B . \quad$ thuringiensis @2g/l, $\quad M$. anisopliae @3g/1 and M. anisopliae @5g/1 giving pupation percentage of $40.00 \%$, $42.50 \%, 45.00 \%$ and $45.00 \%$ respectively and are statistically similar. The pupation success data obtained by bioassay of 6 day old DBM larvae after 144 hours (6 days) after treatment varied from $25.00 \%$ to $87.50 \%$. The percent pupation caused by B. bassiana @4g/l recorded minimum pupation i.e. 25.00\%, which was the least and proved to be most superior treatment. The succeeding percent pupation success was recorded in case of $B$. bassiana@5g/l which was 30.00\%. Higher doses of $B$. thuringiensis $(2 \mathrm{~g} / \mathrm{l})$ and $M$. anisopliae $(5 \mathrm{~g} / \mathrm{l})$ were showing more or less similar results recording percent pupation $42.50 \%$ and $45.00 \%$ respectively. The maximum pupation was recorded with treatment B. bassiana @3g/l (62.50\%) which was statistically similar with other microbial treatments. Though microbial treatments varied in efficacy with respect to doses but they showed better result in suppressing pupation of larvae as compared to control treatment $(87.50 \%)$ after 6 days of treatment.

Table.1 Effect of microbial insecticides on percent pupation success of 6 days old larva of DBM

\begin{tabular}{|c|c|c|c|c|c|c|c|c|}
\hline & Treatments & Dose & $\begin{array}{c}24 \\
\text { hrs }\end{array}$ & $\begin{array}{c}48 \\
\text { hrs }\end{array}$ & 72 hrs & 96 hrs & $120 \mathrm{hrs}$ & 144 hrs \\
\hline $\mathbf{T}_{1}$ & Bacillus thuringiensis & $1 \mathrm{~g} / \mathrm{l}$ & 0.0 & 0.0 & $\begin{array}{c}12.50 \\
(17.14)^{*}\end{array}$ & $\begin{array}{c}42.50 \\
(40.92) * b\end{array}$ & $\begin{array}{c}55.00 \\
(48.24) * c\end{array}$ & $\begin{array}{c}60.00 \\
(51.36) * c\end{array}$ \\
\hline $\mathbf{T}_{2}$ & Bacillus thuringiensis & $1.5 \mathrm{~g} / \mathrm{l}$ & 0.0 & 0.0 & $\begin{array}{c}12.50 \\
(17.14)\end{array}$ & $\begin{array}{c}40.00 \\
(39.26) \mathrm{ab}\end{array}$ & $\begin{array}{c}40.00 \\
(39.26) \mathrm{abc}\end{array}$ & $\begin{array}{c}52.50 \\
(46.73) \mathrm{c}\end{array}$ \\
\hline $\mathbf{T}_{\mathbf{3}}$ & Bacillus thuringiensis & $2 / 1$ & 0.0 & 0.0 & $\begin{array}{c}7.50 \\
(13.48)\end{array}$ & $\begin{array}{c}35.00 \\
(36.31) a b\end{array}$ & $\begin{array}{c}42.50 \\
(40.91) a b c\end{array}$ & $\begin{array}{c}42.50 \\
(40.91) a b c\end{array}$ \\
\hline $\mathbf{T}_{4}$ & Beauveria bassiana & $3 g / 1$ & 0.0 & 0.0 & $\begin{array}{c}30.00 \\
(30.66)\end{array}$ & $\begin{array}{c}55.00 \\
(48.05) \mathrm{b}\end{array}$ & $\begin{array}{c}62.50 \\
(52.90) \mathrm{c}\end{array}$ & $\begin{array}{c}62.50 \\
(52.90) \mathrm{c}\end{array}$ \\
\hline T5 & Beauveria bassiana & $4 g / 1$ & 0.0 & 0.0 & $\begin{array}{c}15.00 \\
(21.20)\end{array}$ & $\begin{array}{c}15.00 \\
(21.20) \mathrm{a}\end{array}$ & $\begin{array}{c}22.50 \\
(28.07) \mathrm{ab}\end{array}$ & $\begin{array}{c}25.00 \\
(30.07) \mathrm{a}\end{array}$ \\
\hline $\mathbf{T}_{6}$ & Beauveria bassiana & $5 g / 1$ & 0.0 & 0.0 & $\begin{array}{c}17.50 \\
(22.86)\end{array}$ & $\begin{array}{c}30.00 \\
(32.60) \mathrm{ab}\end{array}$ & $\begin{array}{c}30.00 \\
(32.60) \mathrm{ab}\end{array}$ & $\begin{array}{c}30.00 \\
(32.60) \mathrm{ab}\end{array}$ \\
\hline $\mathbf{T}_{7}$ & Metarhizium anisopliae & $3 g / 1$ & 0.0 & 0.0 & $\begin{array}{c}20.00 \\
(24.36)\end{array}$ & $\begin{array}{c}35.00 \\
(36.11) \mathrm{ab}\end{array}$ & $\begin{array}{c}45.00 \\
(42.14) \mathrm{abc}\end{array}$ & $\begin{array}{c}52.50 \\
(46.73) c\end{array}$ \\
\hline $\mathbf{T}_{8}$ & Metarhizium anisopliae & $4 \mathrm{~g} / 1$ & 0.0 & 0.0 & $\begin{array}{c}20.00 \\
(24.36)\end{array}$ & $\begin{array}{c}35.00 \\
(36.11) a b\end{array}$ & $\begin{array}{c}52.50 \\
(46.80) b c\end{array}$ & $\begin{array}{c}52.50 \\
(46.80) \mathrm{c}\end{array}$ \\
\hline $\mathbf{T}_{9}$ & Metarhizium anisopliae & $5 g / 1$ & 0.0 & 0.0 & $\begin{array}{c}10.00 \\
(15.49)\end{array}$ & $\begin{array}{c}32.50 \\
(31.27) \mathrm{ab}\end{array}$ & $\begin{array}{c}45.00 \\
(42.14) \mathrm{abc}\end{array}$ & $\begin{array}{c}45.00 \\
(42.14) \mathrm{abc}\end{array}$ \\
\hline $\mathbf{T}_{10}$ & Untreated control & - & 0.0 & 0.0 & $\begin{array}{c}40.00 \\
(39.26)\end{array}$ & $\begin{array}{c}87.50 \\
(69.98) c\end{array}$ & $\begin{array}{c}87.5 \\
(69.98) \mathrm{d}\end{array}$ & $\begin{array}{c}87.50 \\
(69.98) \mathrm{d}\end{array}$ \\
\hline & \multicolumn{2}{|l|}{$\mathrm{SE}(\mathrm{d})$} & - & - & - & 9.09 & 7.46 & 6.91 \\
\hline & \multicolumn{2}{|l|}{$\mathrm{CD}$ at $5 \%$} & - & - & NS & 18.57 & 15.25 & 14.11 \\
\hline
\end{tabular}

*Figures in parentheses are angular transformed values 
Fig.1 Effect of different doses of microbial insecticides on the pupation success of diamondback moth after 144 hours( 6 days) after treatment

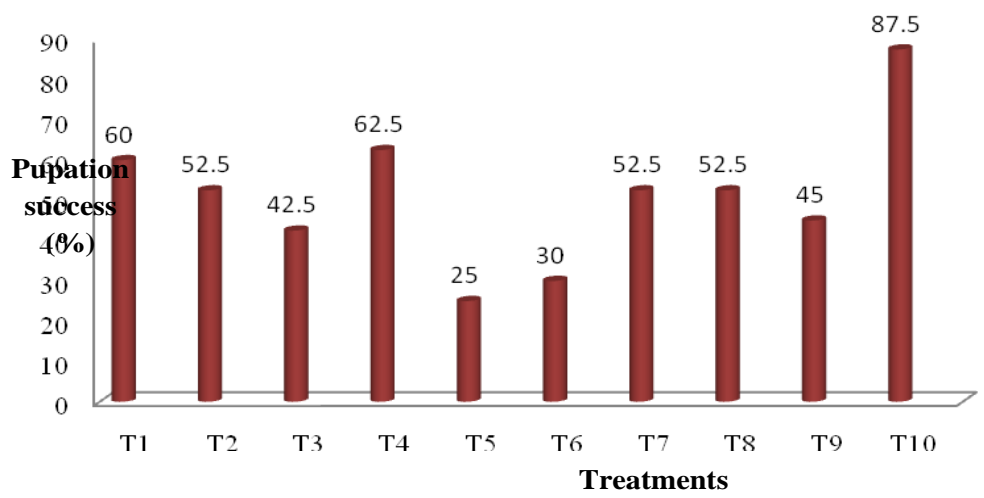

Taking the above results into consideration, it can be stated that the higher doses of $B$. bassiana i.e., at $4 \mathrm{~g} / 1$ and $5 \mathrm{~g} / 1$ were the most effective in suppressing pupation of diamondback moth larvae. The result is in partial confirmation that B.bassiana was most effective showing delayed pupation with an increase in concentration to Spodoptera littoralis and Agrotis ipsilon larvae as given by El- Hawary and El-Salam (2009) and least pupation occur in tobacco caterpillar, Spodoptera litura (Fab.) larvae i.e. $43.33 \%$ when treated with highest concentration of B.bassiana as stated by Malarvannan et al., (2010). Partial similarity in result also could be seen as documented by Torrado-León et al., (2006) that interference in the molting process of nymphs occurred when treated with $B$. bassiana in nymphs of $B$. tabaci. Few pupae moulted from treated larvae showed deformities and died. Similar results of earlier scientists were seen as reported by Kpindou et al., (2012) that some of the Helicoverpa armigera pupae resulting out of the larvae inoculated with isolates of $M$. anisopliae were deformed and dead. It was also reported that $B$. bassiana treated in $S$. litura resulted in malformed pupal stages (Malarvannan et al., 2010).
In conclusion the lower pupation success was observed with all the microbial treatments in comparison to the untreated control treatment. Pupation decreased effectively when 6 day old larvae were exposed to the different doses of microbial formulations. The two higher doses of Beauveria bassiana i.e., $4 \mathrm{~g} / \mathrm{l}$ and $5 \mathrm{~g} / \mathrm{l}$ were the superior treatments. Effectiveness of the other two microbial insecticides i.e., Metarhizium anisopliae and Bacillus thuringiensis could be seen with their higher doses.

\section{References}

Ankersmit, G.W. (1953).DDT resistance in Plutellama culipennis (Lep.) in Java. Bulletin of Entomological Research,44: 421- 425.

Castillo, L.E., E. de la Cruz, and Ruepert, C. (1997). Ecotoxicology and pesticides in tropical aquatic ecosystems of Central America. Environmental Toxicology and Chemistry, 16:41-51.

El-Hawary, F.M. and El-Salam, A.M.E. (2009). Laboratory bioassay of some entomopathogenic fungi on Spodoptera littoralis (Boisd.) and Agrotisipsilon (Hufn.) larvae (Lepidoptera: Noctuidae). Egyptian Academic Journal 
of Biological Science, 2(2): 1-4.

Fletcher, T.B. (1914)Some south Indian insects and other animals of importance considered especially from an economic point of view. Superintendent, Government Press, Madras, pp. 565.

Gill, C., Kaur, S. \& Joia, B.S. (2008).Efficacy of new insecticides for the management of diamondback moth, Plutella xylostellaL. on cauliflower and cabbage.Journal Insect Science,21(2): $171-177$.

Kpindou, O.D., Djegui, D.A., Glitho, I.A.\&Tamò, M. (2012).Sensitivity of Helicoverpa armigera (Hübner) (Lepidoptera: Noctuidea) to the entomopathogenic fungi, Metarhizium anisopliae and Beauveria bassiana in laboratory. ARPN Journal of Agricultural and Biological Science, 7: 1007-1015.

Krishnakumar, N.K., Srinivasan, Suman, C.L. \& Ramachander, P.R. (1986).Optimum control strategy of cabbage pest from a chemical control trial. Progressive Horticulture, 18: 104-110.

Malarvannan, S., Murali, P.D., Shanthakumar, S.P., Prabavathy, V.R.\& Nair, S. (2010). Laboratory evaluation of the entomopathogenic fungi, Beauveria bassiana against the Tobacco caterpillar, Spodoptera litura Fabricius (Noctuidae: Lepidoptera). Journal of Biopesticides, 3(Special issue): 126.

Rejesus, B.M., Fajardo, G.P.\&Inocencio, E.T. (1995).Effectiveness of the IPM [integrated pest management]-DBM [diamondback moth] technology versus farmer's control practice for diamondback moth, Plutellaxylostella control. In 26. PMCP Anniversary and Annual Scientific Meeting, La Trinidad, Benguet (Philippines).

Sharma, S.S., Kalra, V.K. \&Mrig, K.K. (2000).Evaluation of different formulations of Bacillus thuringiensisvarkurstaki and aizawai against Plutella xylostella (L.).Annals Agriculture and Biological Research, 5(1): 67-70.

Talekar, N.S. \& Shelton, A.M. (1993). Biology, ecology, and management of the diamondback moth. Annual Review of Entomology, 38(1): 275-301.

Torrado-León, E., Montoya-Lerma, J.\& Valencia-Pizo, E. (2006).Sublethal effects of Beauveria bassiana (Balsamo) Vuillemin (Deuteromycotina: Hyphomycetes) on the whitefly Bemisiatabaci (Gennadius) (Hemiptera: Aleyrodidae) under laboratory conditions. Mycopathologia, 162(6): 411-419.

Vandenberg, J.D., Shelton, A.M., Wilsey, W.T.\& Ramos, M. (1998).Assessment of Beauveria bassiana sprays for control of diamondback moth (Lepidoptera: Plutellidae) on crucifers. Journal of Economic Entomology, 91(3): 624-630.

\section{How to cite this article:}

Subhadip Sen, Nilima Karam and Singh, K. I. 2021. Efficacy of Some Microbial Insecticides on Pupation Success of Diamond Back Moth (Plutella xylostella L.). Int.J.Curr.Microbiol.App.Sci. 10(01): 3083-3087. doi: https://doi.org/10.20546/ijcmas.2021.1001.358 